are now on high dose therapy and this may affect their consent to treatment.

columns
BRITISH MEDICAL ASSOCIATION \& ROYAL PHARMACEUTICAL SOCIETY OF GREAT BRITAIN

(2000) British National Formulary. London \&

Wallingford: BMJ \& Pharmaceutical Press.

THOMPSON, C. (1994) The use of high-dose antipsychotic medication. British Journal of Psychiatry, 164, 448-458.

Dr Camilla Haw Consultant Psychiatrist, Mrs Jean Stubbs Head of Pharmacy, St Andrew's Hospital, Billing Road, Northampton NN1 5DG

\section{New mental health information strategy}

Sir: Elphick (Psychiatric Bulletin, November 2000, 24, 426-428) stated a true picture of the difficulties in bringing health information strategies into the forefront of psychiatry. He reiterated that more clinicians need more informatics training (NHS Executive, 1999). Unless the clinicians play a part in the frontline developments we will never have a good operational system. With these ideas in mind I would like to inform like-minded clinicians that there are opportunities to be trained. I am currently on a Diploma in Medical Informatics course which the forward thinking Royal College of Surgeons in Edinburgh have started in October 2000. This involves 12 modules (at about 75 hours per module) starting from an introduction to 'information' and leading to proficiencies in databases, telemedicine, electronic health records and other computer and web-related medical topics. You need a computer and connection to the internet. Apart from the initial weekend in Edinburgh and a final week in Edinburgh (2-5 years later) you can do everything else on-line. The course is challenging and lateral thinking is a useful advantage as concepts are quite wide-ranging in the introductory module.

I suggest a look on the Royal College of Surgeon's website (http://www. rcsed.ac.uk) for further information.

NHS EXECUTIVE (1999) Learning to Manage Health Education: A Theme for Clinical

Education. Enabling People Programme. Bristol: NHS Executive South and West.

Stefan Kolowski Specialist Registrar in Old Age and Adult Psychiatry, Taunton and Somerset Partnership Trust, Rydon House Mental Health Unit, Cheddon Road, TauntonTA2 7AZ

\section{Shakespeare and beef}

Sir: Given the current topicality of concerns about the safety or otherwise of beef, both in this country and in continental Europe, I was most interested to note the following exchange between Sir Andrew Aguecheek and Sir Toby Belch in Shakespeare's Twelfth Night (Act I, Scene III)

SirToby: O knight, thou lack'st a cup of canary! When did I see thee so put down?

Sir Andrew: Never in your life, I think; unless you see canary put me down. Methinks sometimes I have no more wit than a Christian or an ordinary man has; but I am a great eater of beef, and I believe that does harm to my wit. SirToby: No question.

I have always been an admirer of Shakespeare's descriptions of medical and psychiatric conditions, but can it be that in this case, as in so many others, he has once again exhibited remarkable prescience?

Peter Childs Consultant Psychiatrist, Department of Psychiatry, Royal South Hants Hospital, Graham Road, Southampton SO14 OYG

\section{Managers' hearings and patients' rights}

Sir: I read Gregory's opinion (Psychiatric Bulletin, October 2000, 24, 366-367) and Kennedy's humorous editorial reply (Psychiatric Bulletin, October 2000, 24, 361-362) with interest. As a practising clinician and long time medical member of the mental health review tribunal I would like to make the following points

Manager's tribunals have no discretionary powers. They must decide on the legality of the section, continue if it is legal, discharge if it is not. Kennedy is right that discharges by managers are rare, I believe the national figure is less than $1 \%$ but there is a wide variation, with some trusts having a figure above $20 \%$. If there are a significant number of illegal sections this is a cause for enquiry. I suspect the truth is that a minority of managers overstep their remit.

Issues of medication, side-effects, polypharmacy, prescribing within British National Formulary limits and consent to treatment (Gregory) are all matters that managers should concern themselves with. They should ensure that their trust has policies and procedures in place to monitor these matters. They have no part in a manager's appeal.

Kennedy is right to raise the matter of legal representation at managers' appeals. This has crept into practice and should be stopped or else the panel must have legal expertise in all cases. Lawyers rehearse their questions for a future tribunal - this runs contrary to the British legal system and is akin to the American system of predisclosure of testimony.

Donald Bermingham Consultant Psychiatrist Hinchingbrooke HealthcareTrust South Building, Primrose Lane, Huntingdon, Cambridgeshire PE29 1WG

\section{the college}

\section{Annual Census of Psychiatric Staffing 1999}

\section{Occasional Paper OP50} £7.50. 74 pp.

This eighth annual census undertaken by the Royal College of Psychiatrists relates to psychiatric staffing in England, Scotland, Wales and Northern Ireland as at 30 September 1999. For the first time the assumptions made in producing the census are clearly given.

The College has confidence that the census provides the most accurate picture we have of psychiatric staffing in the UK.
This is vital information as we work towards producing an effective response to the National Service Framework for Mental Health and the NHS National Plan, and their respective workforce expansion requirements. The data collected in the census have a direct bearing on the College negotiations with the NHS Executive with respect to the number of national training numbers that remain within the speciality, or are added or withdrawn from its pool.

\section{Comment}

There has been an overall increase in consultant posts with growth rates varying from $4.6 \%$, England, 7.4\%, Scotland, under $1 \%$ in Wales and a slight reduction in Northern Ireland by $5 \%$. There is considerable regional variation. The North West and Mersey have over $20 \%$ vacant posts, compared with $17 \%$ in Yorkshire, but under 8\% in East Anglia, Oxford, Wessex and all of Scotland except the West. Compared with last year, the vacancy rate generally is coming down despite the creation of new posts. There is also variation between specialities. In child and adolescent psychiatry recruitment is improving in most areas except Scotland. The same is true of forensic psychiatry where $16 \%$ of posts in Scotland are vacant, but empty posts are reducing everywhere else. Learning 